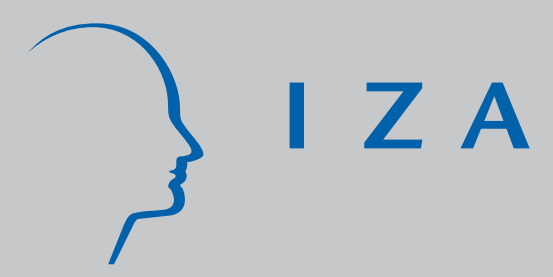

IZA DP No. 5848

Where to Put the Kids? Effects of Type of Non-parental Child Care on Pre-teen Skills and Risky Behavior

Nabanita Datta Gupta

Marianne Simonsen

July 2011

Forschungsinstitut zur Zukunft der Arbeit Institute for the Study of Labor 


\title{
Where to Put the Kids? \\ Effects of Type of Non-parental Child Care on Pre-teen Skills and Risky Behavior
}

\author{
Nabanita Datta Gupta \\ Aarhus University \\ and IZA \\ Marianne Simonsen \\ Aarhus University \\ and IZA
}

Discussion Paper No. 5848

July 2011

IZA

P.O. Box 7240

53072 Bonn

Germany

Phone: +49-228-3894-0

Fax: +49-228-3894-180

E-mail: iza@iza.org

\begin{abstract}
Any opinions expressed here are those of the author(s) and not those of IZA. Research published in this series may include views on policy, but the institute itself takes no institutional policy positions.

The Institute for the Study of Labor (IZA) in Bonn is a local and virtual international research center and a place of communication between science, politics and business. IZA is an independent nonprofit organization supported by Deutsche Post Foundation. The center is associated with the University of Bonn and offers a stimulating research environment through its international network, workshops and conferences, data service, project support, research visits and doctoral program. IZA engages in (i) original and internationally competitive research in all fields of labor economics, (ii) development of policy concepts, and (iii) dissemination of research results and concepts to the interested public.
\end{abstract}

IZA Discussion Papers often represent preliminary work and are circulated to encourage discussion. Citation of such a paper should account for its provisional character. A revised version may be available directly from the author. 


\section{ABSTRACT}

\section{Where to Put the Kids? Effects of Type of Non-parental Child Care on Pre-teen Skills and Risky Behavior*}

This paper investigates pre-teenage effects of the choice of type of non-parental child care at age three (preschool relative to more informal family day care). We exploit a Danish panel data child survey merged with administrative records along with a pseudo-experiment that generates variation in the take-up of preschool across municipalities. As outcomes, we consider measures of overall and risky behavior in addition to objective and self-evaluated abilities. We find no strong evidence that one type of non-parental care outperforms the other, though children who have been placed in preschool tend to like school better.

JEL Classification: J13

Keywords: child care, skills, risky behaviors, evaluation

Corresponding author:

Nabanita Datta Gupta

Aarhus School of Business

Aarhus University

Frichshuset

Hermodsvej 22

8230 Åbyhøj

Denmark

E-mail: ndg@asb.dk

\footnotetext{
* Access to the Danish Longitudinal Survey of Children was granted us by the Danish National Centre for Social Research. We thank Mette Lausten for data assistance, Niels Glavind from Bureau 2000 for supplying crucial information on childcare guarantees and Helena Skyt Nielsen, David Ribar, and Liz Washbrook for valuable comments. We appreciate comments from seminar participants at Aarhus University, participants at the 2010 EALE/SOLE conference, the 2010 NCoE workshop, and the 2010 APPAM conference.
} 


\section{Introduction}

It is becoming increasingly clear that childhood experiences and interventions are pivotal for the development of both cognitive and behavioral skills. A large literature focuses on the effects on child development of non-parental versus parental care. See Almond and Currie (forthcoming), Blau and Currie (2006), Currie (2001) and Ruhm (2004) for excellent surveys and Baker et al. (2008) and Havnes and Mogstad (forthcoming) for recent studies that exploit plausible exogenous variation in access to non-parental care. For many parents, however, the relevant choice is not whether to place the child in non-parental care but which type to choose. We bring evidence from a regime with large-scale publicly provided universal care. $85 \%$ of the three-year-old Danish children considered in this paper are enrolled in some type of non-parental care, and when enrolled spend around 33 hours per week in non-parental care. In comparison, Blau and Currie (2006) report that $75 \%$ of US children aged 0-4 whose mothers were employed in 1999 were in some form of non-parental care.

Expensive early childhood programs aimed at disadvantaged children have proven to be effective, whereas remedial programs introduced later in life are not; see e.g. Heckman (2008). But what do we know about the effectiveness of the kind of non-parental care for the population of children as a whole? Though there is not complete agreement with regards to the results and though most work compare non-parental care to parental care, recent literature (Bernal and Keane (2008); Datta Gupta and Simonsen (2010); Gregg, Washbrook, Propper, and Burgess (2005); Magnuson, Ruhm, and Waldfogel (2007)) suggests that it is important to distinguish between different types of nonparental care. Except for the paper by Datta Gupta and Simonsen (2010) none of these papers have access to variation that drives the mode of non-parental child care but not outcomes. Most of these studies also investigate effects on cognitive outcomes, although recent literature (see for example 
Heckman et al. (2006) and Grönquist, Öckert and Vlachos (2010)) suggests that non-cognitive outcomes may be just as important.

Our paper contributes to the literature investigating the question of mode of non-parental care by following up on the short-term analysis by Datta Gupta and Simonsen (2010). Specifically, we consider the effects at age 11 of being enrolled at age three in relatively high quality formal center based child care vis-à-vis more informal care ${ }^{1}$ (family day care) where a child-minder in her own home cares for a small group of children from several families, comparable to an out-of-home nanny. ${ }^{2}$ In contrast to Datta Gupta and Simonsen (2010) who only consider behavioral outcomes at age seven and find that preschool is beneficial, we analyze both objective and self-reported measures of cognitive and non-cognitive skills as well as risky behavior such as smoking, drinking, petty theft and vandalism. In contrast to most of the existing literature, we exploit plausible exogenous variation in the take-up of preschool that stems from a pseudo-experiment generating waiting lists for preschool in some municipalities while guaranteeing open slots in others.

Estimations are carried out using a longitudinal representative survey following children born in September and October of 1995. The survey holds information about children, mothers, and fathers and is linked to highly reliable administrative registers providing us with crucial background information about the parents and their labor market behavior. We interpret the estimated effects as those of early child care enrollment including any indirect effects that arise because children in one

\footnotetext{
${ }^{1}$ Bernal and Keane (2008) uses the term informal care about care by relatives or non-relatives in non-center-based settings.

${ }^{2}$ Blau and Currie (2006) report that $28 \%$ of US children aged 0-4 whose mothers were employed were in non-relative care that includes family day care, nannies, and baby sitters.
} 
type of care follow different paths or are exposed to different environments and types of upbringing than children in other types of care, after the age of three. Roughly speaking, because children enrolled in informal care shift into preschool later on, we measure the effect of enrolling in preschool at age three rather than at age four. We find that eleven-year-old children who have been enrolled in informal family day care at age three fare just as well as children who have been in preschool but tend to like school less. In particular, our results indicate that the age-seven-gaps in behavioral outcomes due to choice of type of child care are closed at age eleven. Families are either fully capable of dealing with these initial behavioral differences or exposure to primary school and after-school care for up to five years equalizes (or institutionalizes) children, which dilutes the initial effects.

The paper is organized as follows: Section 2 describes our data and the institutional framework and Section 3 discusses the empirical framework. Results are shown in Section 4, Section 5 provides sensitivity analyses, and Section 6 concludes.

\section{Data and Institutional Framework}

We exploit a panel dataset on children's outcomes, modes of care, and parental background information, known as the Danish Longitudinal Survey of Children (DALSC). The data consist of repeated surveys of the primary parent of initially roughly 6,000 children born between 15 September and 31 October 1995. The first survey took place when the children were 6 months old (1996), the second when they were around 31/2 (1999), the third at age $71 / 2$ (2003) when the children are expected to have started first grade (age 7 in Denmark), and the fourth at age 111/2 (2007). The fathers of these children were surveyed separately in some of these waves. In addition, a special segment on children's health and welfare was added to the mother survey in 2003 and 2007 and the 
children themselves were surveyed in the 2007 wave. The surveyed individuals, be it mothers, fathers, or children, are alone with the interviewer during the interview. This is obviously important for the validity of the survey information. Unfortunately, as is common with surveys, the data suffer from attrition. Appendix A discusses this at length.

\section{FIGURE 1}

TIMING OF SET-UP

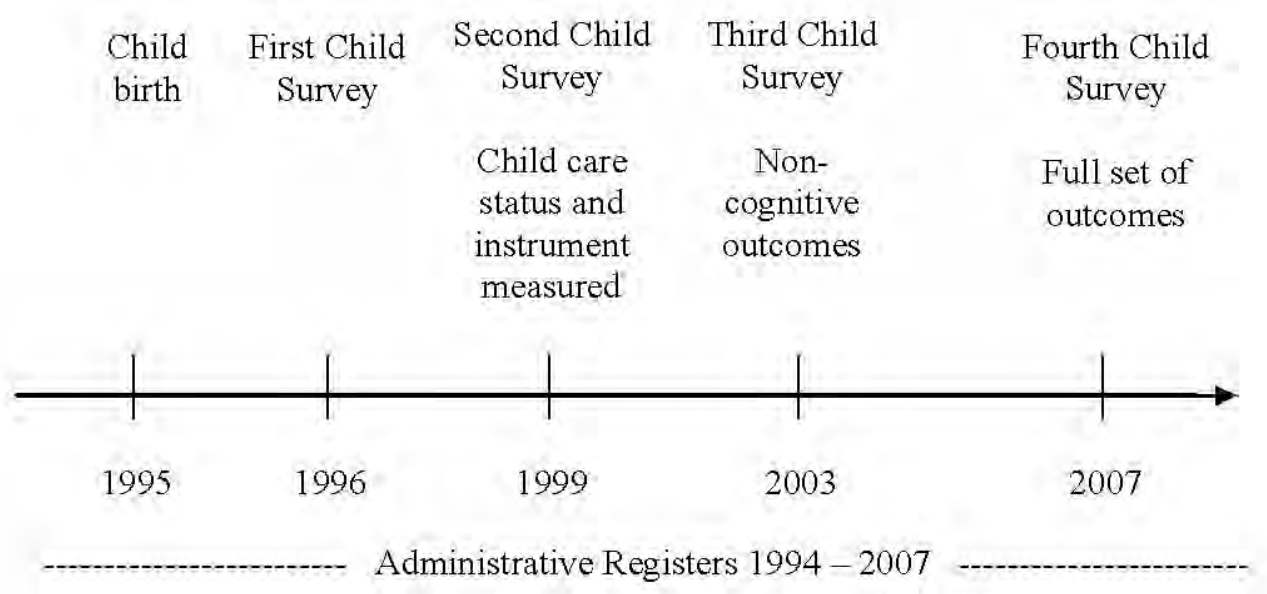

The survey data have been merged to administrative registers holding information on parents' educational attainment, labor market status, hours of work, wages and income for the period 19942007. Self-reported child care enrollment status is measured in 1999 and child outcomes are recorded in 2003 and 2007. Unfortunately, the sets of child outcomes are not fully overlapping; cognitive measures are, for example, only available in the 2007 survey round. Furthermore, our instrument for child care choice is available in 1999 only, which precludes an analysis of the effects of the timing of different types of care. Figure 1 above shows the timing of our set-up. In what follows, we will consider exposure to child care at age three and focus on the subsequent child outcomes measured at age eleven.

\subsection{Child Care in Denmark}


Danish child care is for the major part publicly provided, paid for, and organized within the 271 municipalities. Municipalities provide nurseries for children 0-2 year old children, preschools for children 3-6 year old children and after-school programs for school children, all of which are center based. In addition, municipalities organize family day care that takes place in private homes for children below the age of $14 .^{3}$ The municipality is free to decide on the distribution of the different types of care but must cover 'local needs' in terms of number of slots at a given age. Here we focus on care for three-year-olds: preschool and family day care. At age three, about $66 \%$ of children are enrolled in preschool and $16 \%$ are in family day care. About $15 \%$ of the children are taken care of at home. In the following, we will ignore the small fraction of children participating in private and other specialized care.

Preschool programs in Denmark (along with other Nordic countries) are characterized both by high quality and expenditure levels per capita compared to other countries and usage, see Datta Gupta, Smith and Verner (2008). Requirements of qualifications of child care staff are extensive compared to other EU (and OECD) countries and the number of children per staff member is much lower, see OECD’s Family Database. In Danish preschools, the average staff:child ratio is 1:7, whereas in the US and Canada, for example, the corresponding ratio is 1:12 (1:14 for teaching staff), in Spain 1:13, and France 1:19. In fact, according to OECD’s Family Database for 2007, Denmark has the lowest average number of children per staff member in preschools among all OECD countries.

In 1999 (when the children in our sample were three years old), the average yearly expenditures for a slot in center-based preschool for three-year-olds were approximately $\$ 8,000$. This is significantly higher than the expenditures for, for example, the American Head Start Program aimed at low-

\footnotetext{
${ }^{3}$ In reality, though, children in family day care are much younger than 14 , see below.
} 
income families which costs around \$5,000 per year, see Currie (2001), and roughly the same as the expenditures for the universal Canadian child care program, see Baker, Gruber, and Milligan (2008). Family day care is more expensive than center-based preschool; the average yearly costs are about $\$ 10,000 .{ }^{4}$ This is presumably because staff-to-child ratios are higher (minimum of 1:5) for this type of care for the age group in question. Prices are set at the municipality level once a year and hold throughout the municipality for a given type of care. ${ }^{5}$

\section{Preschool and family day care}

The average preschool (that may be integrated with nursery centers for 0-2 year olds) facilitates about 60 children who are split into smaller groups of about 20 children. Each of these preschools employs around 9 permanent teachers plus a number of assistants and other staff, thus allowing for considerable specialization of labor. About $9 \%$ of preschool teachers are male. Preschool teachers in permanent positions must have a degree in teaching (medium length tertiary education or 15-16 years of education) and specialize in young children. The municipalities are required by law to monitor the institutions closely regarding educational content as well as safety and hygiene. Regulation of the former requires ensuring that the personnel have the necessary qualifications, whereas regulation of the latter includes accident-preventing measures, play-grounds, transport, sleeping facilities, toys, hygiene, and insurance schemes. Importantly, institutions are child-centered and focus on socialization rather than a basic skills curriculum. The maximum number of children

\footnotetext{
${ }^{4}$ For $0-2$ year olds, family day care is the cheaper option.

${ }^{4}$ Parents pay a maximum of $33 \%$ of the total costs of providing care, and the price is reduced with lower income and number of siblings enrolled in public care, for either type of care. See Simonsen (2010) for a detailed description of the pricing scheme. In the empirical analysis we condition on the determinants of parental income to account for selection into types of care based on income.
} 
per preschool teacher is determined through collective bargaining between the municipalities and the preschool teachers' trade union (BUPL). The norm for 1999 was set at the 1997 collective bargaining. These institutional details will turn out to be important for our identification strategy described below.

In contrast, non-center-based family day care is care where a child-minder in her home cares for a small group of children from several families, comparable to an out-of-home nanny. $99 \%$ of the child-minders are female. The caregivers are directly employed by the municipality. Again, the municipalities must approve the facilities and the qualifications of the caregiver. There may be up to five children in each home, and in some municipalities the caregiver's own children under the age of three enter into the total number of children in the family day care. The caregiver will then receive compensation from the municipality for taking care of her own children. Caregivers in charge of family day care are not required to have a degree in teaching but are offered shorter (3-week) vocational courses.

\section{Allocation of slots in child care}

All children are eligible for municipality child care, including children born to unemployed parents. ${ }^{6}$ It is in fact illegal to exclude certain groups of children from participating. This means that children's right to child care enrollment is not affected by their parents' transitions in and out of the labor market. Presumably, if child care does contribute to the development of social and academic skills, we may expect such disruptions to be detrimental to learning.

\footnotetext{
${ }^{6}$ The only exception occurs if one of the parents takes formal publicly supported maternity or child care leave aimed at the child in question.
} 
Parents apply for child care (either preschool or family day care) by sending an application to the municipality; the child care institutions are not involved in the allocation process. Thus there is no institutional selection bias. The application process is exactly the same no matter whether parents apply for preschool or family day care. Parents enter the date from which care is needed. Upon application, children enter the waiting list. The municipality can decide whether birth date or date of application determines seniority and slots are assigned accordingly. 'Degree of need' is specifically not taken into consideration but certain exceptions are made to accommodate special social or pedagogical circumstances such as disabilities and immigrant status. Additionally, a child can jump the waiting list if he or she has older siblings enrolled in municipality provided care. Therefore, we include whether the child is physically disabled, whether the mother is a non-native speaker and the number of older siblings as controls in the analyses below.

Parents may indicate whether they prefer preschool or family day care. However, children with the highest seniority are assigned the first open slot. If possible, municipalities will accommodate parents' preferences, but parents do not have the right to a specific slot. Parents may decline the offer they are given. ${ }^{7}$ If birth date is used to determine seniority, the only consequence of declining a slot is a delay in the time until the child can enter child care, i.e., once the parents reapply, children will get the same position on the waiting list. It is clearly uncertain when the next slot is available and whether it will be of the preferred type. If seniority is determined based on time on the waiting list, the municipality may decide to blacklist parents for a limited period. ${ }^{8}$ Once the child is enrolled in care, he or she will no longer appear on the waiting list for alternative slots. This means

\footnotetext{
${ }^{7}$ We only have information about the type of slot accepted by the parents, not the slot offered at the outset.

${ }^{8}$ Unfortunately, we do not know which municipalities choose which seniority criterion.
} 
that once a child is enrolled in, for example, family day care, he or she does not have the right to move to preschool (but some municipalities may allow moves anyway).

This system generates four potential groups of parents: 1) Those who were granted a slot in the preferred type of care, 2) those who were granted a slot in the non-preferred type of care and declined the offer, 3) those who are indifferent, and 4) those who were granted a slot in the nonpreferred type of care and accepted the slot (i.e. those who weakly prefer to accept the nonpreferred slot now compared to declining in order to wait for another slot that may be of the preferred type). It is therefore unlikely to be - unconditionally - random which children end up in which types of care. Presumably, parents who have strong preferences for a given type of care and are willing and capable of waiting for a slot are different from parents who accept a non-preferred slot. Hence, their children may differ as well.

\section{Guaranteed access to preschool (GAPS)}

Because of the likely non-random selection into types of care, we look for variation in the take-up of preschool that is unrelated to child outcomes. We exploit the fact that the municipality must provide the 'necessary' number of slots in day care but are free to decide on the distribution of slots in preschool vs. family day care. Therefore, some municipalities are capable of providing guaranteed access to preschool (GAPS). This means that all children have the right to a preschool slot within the municipality (but not to a specific slot). ${ }^{9}$ This policy generates potential variation in the take-up of preschool across municipalities. If parents on average value preschool over and above family day care, we should expect GAPS to increase the take-up of preschool. The instrument

\footnotetext{
${ }^{9}$ More precisely, the policy guarantees access to center based care (nurseries and preschools). For our purposes, the important feature is access to preschool.
} 
is measured in 1999. This corresponds to the point in time when the parents decide whether or not to enroll their child into preschool.

Two sets of agents can affect whether parents face GAPS: the local government and the parents themselves. What determines whether a municipality provides GAPS? We will argue that it is optimal from the local government's point of view to aim for exactly meeting demand for slots in preschool: Having open slots is clearly costly in terms of teacher salaries and rent which the municipality (by definition of open slots) is already committed to paying. On the other hand, providing too few slots causes dissatisfaction among municipality inhabitants and may affect voting behavior in the future. Further, remember that, as described above, prices as well as the maximum number of children per preschool teacher in a municipality, the dominant quality parameter, are fixed within a given year. Municipalities can therefore not guarantee access to preschool in a calendar year by lowering quality, and there are large fixed costs associated with establishing new preschools. Nor can parents, in the short run, be forced to cover the costs of a lower-than-predicted number of children enrolled in preschool.

Therefore, GAPS information provides us with variation in the take-up of preschool which is not a parental choice variable, and it has, arguably, no causal effect on child outcomes by itself. Of course, parents with more to gain from GAPS settle accordingly. Firstly, according to Simonsen (2010), there is very limited movement to and from municipalities providing advantageous child care policies. Secondly, there is municipality specific variation in child care policies over time, for example driven by changes in the age structure and composition of the population. A couple can therefore not be sure that a municipality will not change its policy. This does not, of course, exclude the possibility that people settle because of child care policies, but it decreases the probability. 
Thirdly, it is unlikely that the child care policy is the main driver for settlement when compared to job opportunities and prices of real property. Furthermore, in our empirical analyses we condition on the number of siblings, which is expected to capture part of the expected gains from living in a municipality with GAPS.

We realize, of course, that child care policies are likely to be correlated with other municipality specific characteristics which may affect, on the one hand, the parents' decision of where to live and, on the other hand, the municipality's capability of and preferences for providing services in general. To counter this, our conditioning set includes municipality characteristics, see below. The critical feature is whether provision of GAPS is correlated with child outcomes. To shed light on this and the degree of selection into GAPS-municipalities, Datta Gupta and Simonsen (2010) estimate a probit for living in a GAPS-municipality conditioning on the variables from their main analyses. In general, very few coefficients are significant at the $5 \%$ level indicating that selection on observable characteristics is a minor problem. There is also no clear evidence that for example highly able parents locate themselves in municipalities providing GAPS.

\section{Interpretation of treatments: Enrollment patterns}

It is important to keep in mind that most children in family day care and preschools have been enrolled in care before the age of three - and they continue in care during school ages (after-school programs). To gain more insights into the enrollment patterns, we augment our survey data with administrative data from Statistics Denmark (the Day Care Register). Unfortunately, these data only cover $80 \%$ of Danish children enrolled in child care which causes some discrepancies between our 
survey data and the register data and makes the latter unsuited for our formal analyses. ${ }^{10}$ Furthermore, the timing of the two data sources is not exactly the same; the survey is collected from February to April, while the register data are from March. From 2004 and forward, the register data are collected in the fall. The data do, however, give a rough picture of prior and later enrollment.

TABLE $2^{\mathrm{a}}$

\section{ENROLMENT PATTERNS}

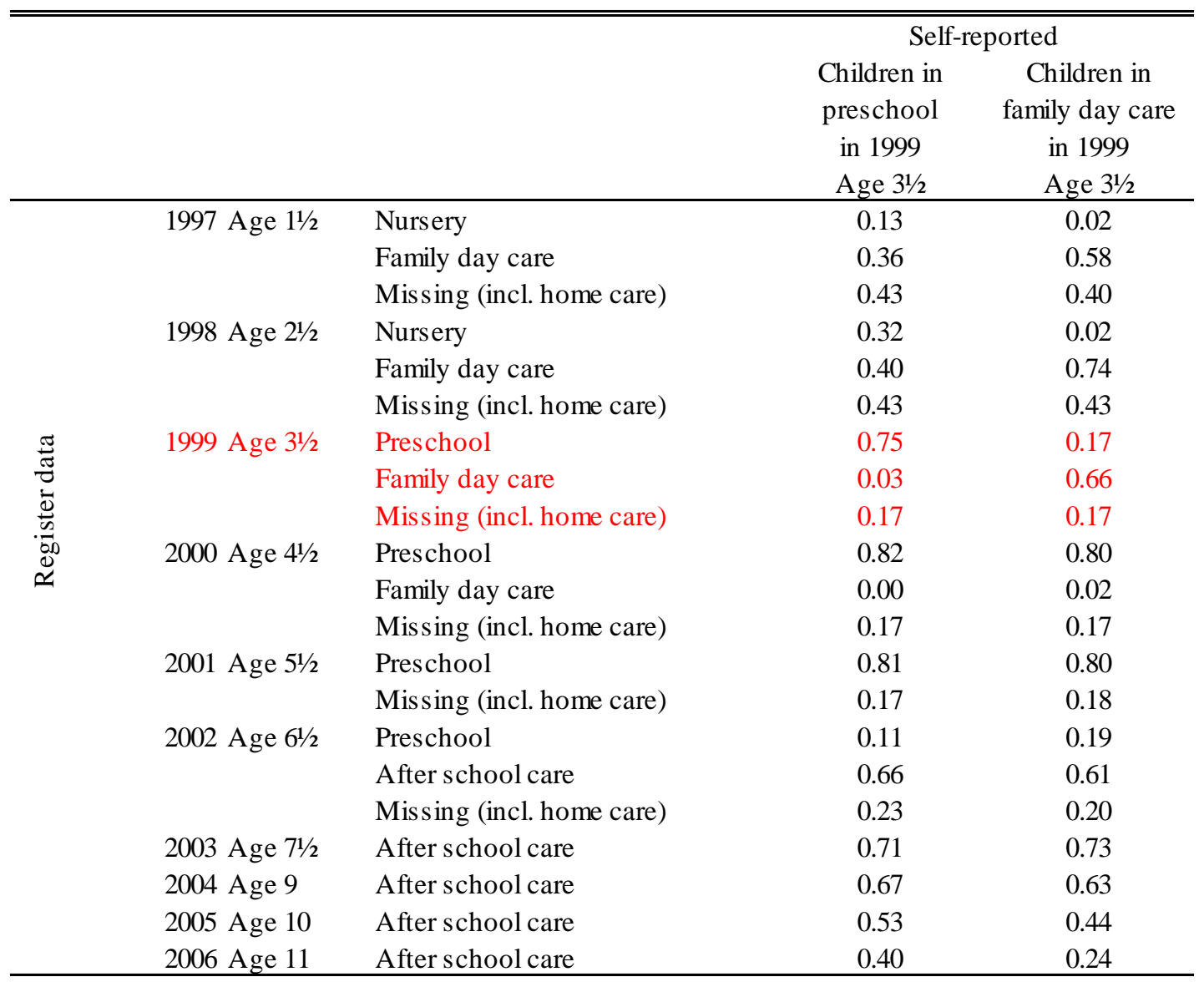

${ }^{a}$ Until 2004, enrolment in register data was recorded in week 10 (March), from 2004 and forward during the fall. Self-reported enrolment in 1999 was recorded in the spring.

\footnotetext{
${ }^{10}$ Prior enrollment is included as a conditioning variable. Whether we include this information or not does not change that conclusions from the empirical analyses.
} 
Table 2 shows enrollment from age $0-11$. Here it is clear that the majority of children in family day care at age $3 \frac{1}{2} 2$ were also in family day care earlier on, whereas children in preschool at age $3 \frac{1}{2}$ have been placed in both family day care and center based nurseries. At age 41/2, most children are in preschool regardless of type of care at age $3 \frac{1}{2}$ but preschool children are more likely to enroll in after school care until the age of 11 . Conditional on prior enrollment, therefore, the treatment "participation in preschool relative to family day care at age 31/2" roughly corresponds to evaluating the effect of about one extra (early) year of preschool combined with a slightly higher propensity to enroll in after school care at ages 10-11. One might argue that an extra early year of preschool is a relatively weak treatment. See, however, the recent work by Chetty et al. (2010) that documents that a single year of high quality early childhood classroom education has long-lasting impacts.

There is a weak tendency for children in family day care at age $3 \frac{1}{2}$ to stay in preschool at age $61 / 2$ and consequently delay school start. This is possibly a consequence of the treatment, though it may also indicate that family day care children are weaker children. Because the register data are suboptimal in our context, it is difficult to make hard conclusions. To account for this, our conditioning set includes a number of child related characteristics.

\subsection{Child Outcomes}

In our empirical analysis we consider a range of outcomes, all measured at age $11 \frac{1 / 2}{2}$ when the children are expected to be in fifth grade. It should be stressed that all outcomes, therefore, are measured at different (later) points in time than our treatment. Had this not been the case, or had the two types of information been linked in the survey, one may have feared that parents would be inclined to rationalize their choice of child care and overestimate good child behavior, which could bias our results below. Also, survey responses may be biased - children may, for example, 
overestimate their abilities - but as long as the bias is unrelated to the treatment we will still get unbiased treatment effects. Table 3 shows means of all outcomes across types of care.

Our first outcome measure is the Strength and Difficulties Questionnaire (SDQ), a behavioral measure known from the child development literature, cf. Goodman (1997). To avoid confusion, denote SDQ measured in 2003 SDQ2003 and SDQ measured in 2007 SDQ2007. The SDQ index is based on emotional symptoms, conduct problems, hyperactivity/inattention problems, and peer relationship problems. In addition to these subscales, a subscale measures pro-social behavior. Parents are asked 25 questions about the child's behavior. Response categories are "not true", "somewhat true” and "certainly true". The five items in each subscale are scored 0 to 2 (where a higher score indicates worse behavior, except for the positive subscale for which the scoring is reversed), giving scores ranging from 0 to 10 for each subscale, summing up to the total difficulties scores ranging from 0 to 40. See www.sdqinfo.com for further details including a list of the questions used to construct the SDQ index.

Although the Strengths and Difficulties Questionnaire is a relatively new instrument, it has already seen widespread use for psychiatric screening of children and adolescents (i.e., Hawes and Dadds, 2004; Klasen et al., 2000; Koskelainen et al., 2000; Mathai et al., 2002; Woerner et al., 2004). Research finds that the SDQ and Rutter questionnaires correlate highly and do equally well in terms of classifying behavior, see Goodman (1997). A closely related measure, the Behavior Problem Index is used in Cunha and Heckman (2008) to investigate the production of cognitive and noncognitive skills. Table 3 indicates that there are no significant differences in SDQ2007 across types of care. Also, Figure 2 shows the distribution of the SDQ2003 and SDQ2007 indices in our sample. 
We see that the distribution of SDQ2007 is shifted to the left compared to the distribution in 2003. Thus children encounter fewer behavioral problems as they grow older. ${ }^{11}$

Our second set of outcomes consists of objective performance measures. One is a multiple choice language test consisting of 34 questions. The other is a multiple choice test of cognitive skills consisting of 40 questions called the Children's Problem Solving or CHIPS test. The test is a nonmath test of logic that asks children to choose among a range of possible figures to complete a logical sequence. The language test thus allows for a maximum of 34 points while students can attain a maximum of 40 points in the CHIPS test. The third measure indicates whether school enrollment has been delayed or grades have been repeated. ${ }^{12}$

\footnotetext{
11 This is true in other countries as well, see www.sdqinfo.org.

${ }^{12}$ Remember that children are expected to be in grade 5 at age $11 \frac{1}{2}$. About four per cent are ahead and $23 \%$ are delayed in terms of progression.
} 
FIGURE 2

\section{DISTRIBUTION OF SDQ INDICES}

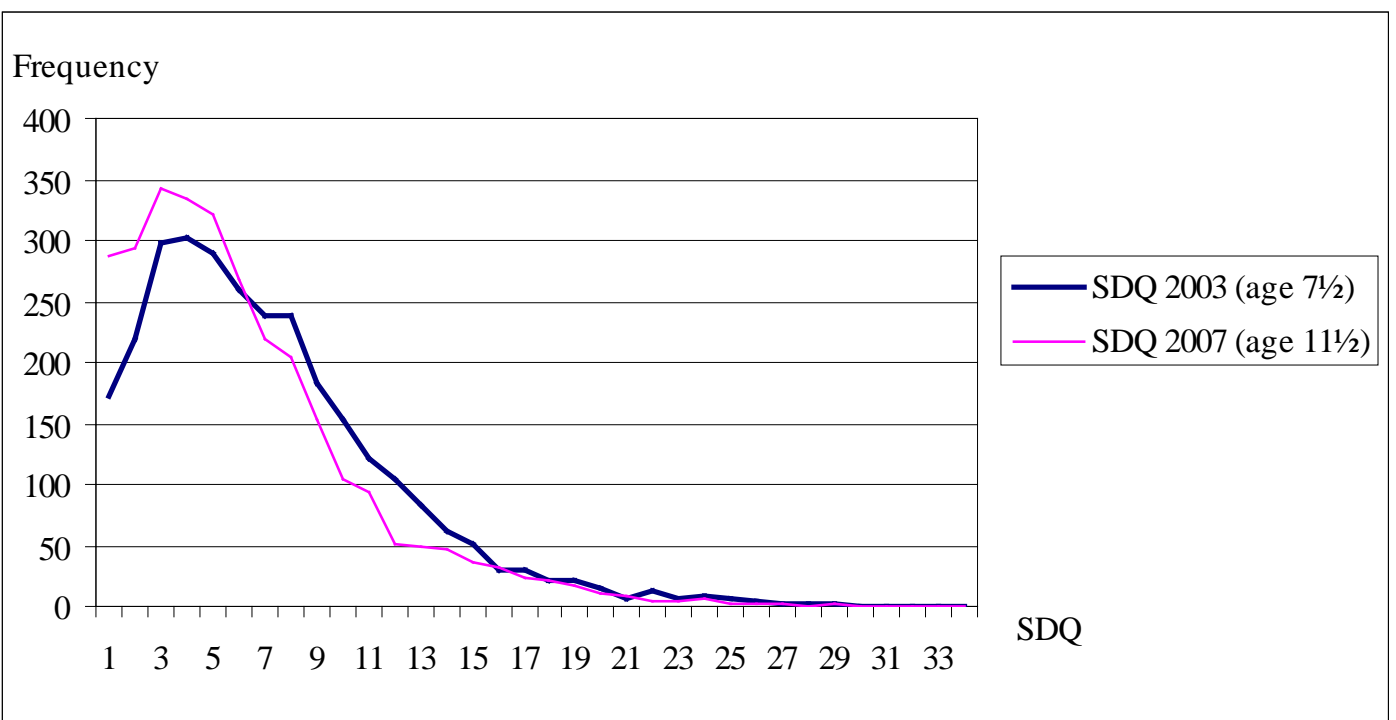

Source: Data used for estimation purposes. SDQ below 14 is 'normal', between 14-16 is borderline, and above 16 is 'abnormal. Danish mean for $11 \frac{1 / 2}{2}$ year olds 5.23, US mean for $11-14$ year olds 7.1 , UK mean for 11-15 year olds 8.2. See www.sdqinfo.org.

This latter measure includes 'academic redshirting'; the phenomenon that school enrollment is postponed in order to allow extra time for socio-emotional or intellectual growth. Preschool experiences are likely to be important for this outcome; a recent paper by Elder and Lubotsky (2009) exploits state-variation in kindergarten entrance age to show that the positive association between late school enrollment and achievement test scores reflects skills accumulation prior to kindergarten. Table 3 indicates that preschool children do significantly better than children in family day care both in terms of the language and the cognitive test. Consistent with the enrollment patterns discussed above, they are also less likely to have experienced late school enrollment or grade repetition. 
The third set of outcomes measures self-evaluated school performance. Children are asked a series of questions about school: "How well do you think you fare academically?”, 13 "How much do you like to go to school”, ${ }^{14}$ "You are good at math. To what extent do you agree?” and "You are good at Danish. To what extent do you agree?”. ${ }^{15}$ We form four binary outcome measures based on these questions: “Excellent academic performance”, “Likes school very much”, “Strongly agree: Good at math", and "Strongly agree: Good at Danish". Clearly these subjective outcomes should be interpreted as a mixture of self-perceived cognitive skills, self-confidence, and ability to adapt to a school environment and demands from authorities. As seen from Table 3, children in preschool at age three have significantly higher self-evaluated math performance at age eleven when compared to children enrolled in family day care. This resonates with the objective performance measures.

\footnotetext{
${ }^{13}$ Responses: “excellent”, “good”, “fair”, “poor”, “do not know”.

${ }^{14}$ Responses: “very much”, “quite a lot”, “average”, “not much”, “not at all”, “do not know”.

${ }^{15}$ Responses to the latter three questions: “”strongly agree”, “agree”, “disagree”, “strongly disagree”, “do not know”.
} 
TABLE $3^{\mathrm{a}}$

OUTCOME MEASURES AT AGE 11 1/2

\begin{tabular}{|c|c|c|c|c|}
\hline & \multicolumn{4}{|c|}{ Mode of child care, age $31 / 2$} \\
\hline & \multicolumn{2}{|c|}{$\begin{array}{c}\text { Family } \\
\text { Day Care }\end{array}$} & \multicolumn{2}{|c|}{ Preschool } \\
\hline & Mean & \# obs & Mean & \# obs \\
\hline \multicolumn{5}{|l|}{ Behavioral measure: } \\
\hline SDQ2003 & $\begin{array}{c}6.79 \\
(5.19)\end{array}$ & 806 & $\begin{array}{c}6.49 \\
(5.04)\end{array}$ & 3,237 \\
\hline SDQ2007 & $\begin{array}{c}5.35 \\
(4.45)\end{array}$ & 533 & $\begin{array}{c}5.18 \\
(4.53)\end{array}$ & 2,038 \\
\hline \multicolumn{5}{|l|}{ Objective performance measures: } \\
\hline Language test & $\begin{array}{l}20.34 \\
(5.38)\end{array}$ & 740 & $\begin{array}{l}21.22 \\
(4.97)\end{array}$ & 3,000 \\
\hline Cognitive skills test & $\begin{array}{l}28.84 \\
(5.52)\end{array}$ & 750 & $\begin{array}{r}29.25 \\
(5.26)\end{array}$ & 3,031 \\
\hline Delayed school entry (or progress) (0/1) & 0.26 & 760 & 0.22 & 3,083 \\
\hline \multicolumn{5}{|l|}{ Self-evaluated school performance: } \\
\hline Excellent academic performance (0/1) & 0.36 & 727 & 0.37 & 2,930 \\
\hline Likes school very much (0/1) & 0.25 & 727 & 0.24 & 2,931 \\
\hline \multicolumn{5}{|l|}{ Strongly agree: } \\
\hline Good at math $(0 / 1)$ & 0.37 & 727 & 0.43 & 2,929 \\
\hline Good at Danish (0/1) & 0.50 & 727 & 0.50 & 2,930 \\
\hline \multicolumn{5}{|l|}{ Risky behavior measures: } \\
\hline Ever smoked (0/1) & 0.05 & 727 & 0.04 & 2,930 \\
\hline Ever drunk alcohol (0/1) & 0.08 & 727 & 0.08 & 2,929 \\
\hline Petty theft and vandalism (0/1) & 0.14 & 727 & 0.14 & 2,930 \\
\hline
\end{tabular}

${ }^{a}$ Bold indicates that means are significantly different at 5\% level from that of family day care, while italic indicates significance at 10\% level Std. dev. for non-binary outcomes in soft brackets.

Our final set of outcomes relates to risky behavior such as smoking, drinking and petty theft and vandalism. There is a large body of research showing that both smoking and drinking increases the likelihood of poor health and economic outcomes later in life. Similarly, smoking and drinking may induce large social costs. In the survey, children are asked “Have you ever smoked?” and "Have you ever drunk alcohol" and we use these outcomes directly in the analyses. To estimate petty theft and vandalism, we exploit that children are asked whether they have stolen money or smaller objects from parents, friends or shops and whether they have ever painted graffiti or destroyed other 
people's property on purpose. On the outset, there are no significant differences in responses across types of care. Of course, some children may be more honest than others and the implicit assumption is that the degree of honesty does not depend on child care enrollment at age three (though it might since child care enrollment affects behavior at age seven, see Datta Gupta and Simonsen (2010)).

\section{Empirical Framework}

This section first discusses our parameter of interest and then considers identification. We consider the effects on child outcomes at age eleven of participating at age three in preschool compared to family day care. Note that family day care and preschool are policy relevant in the sense that the majority of Danish three-year-old children are enrolled in these particular types of care. We also only include children whose mother filled in the questionnaire. ${ }^{16,17}$

\section{Effects of type of child care}

Consider participation in preschool, $P S$, relative to family day care for the group of children enrolled in some municipality provided program. Let $P S=1$ indicate preschool participation, whereas $P S=0$ indicates family day care. Let $O_{1}$ be the potential outcome in family day care and

\footnotetext{
${ }^{16}$ This is the case for $99 \%$ of the children in the survey.

${ }^{17}$ The $15 \%$ of children who are in home care and excluded from the analysis have parents with slightly lower education and a looser connection to the labor market. Their mothers are more likely to smoke, be single, and to be non-native speakers. OLS regressions comparing preschool and family day care to home care show no association between family day care enrolment (relative to home care) and outcomes but preschool children perform significantly better than children in home care in terms of self-reported math and Danish skills.
} 
$O_{1}$ be the potential outcome in preschool. We consider the average effect of preschool participation for the group of children enrolled in preschool:

$$
E\left[O_{1}-O_{0} \mid P S=1\right]
$$

Our parameter of interest (1) should be interpreted as the effects of preschool relative to family day care, including any effects arising via parents' different labor market behavior and income in the two states in the year of treatment. Given that we condition on enrollment in non-parental care, we are, however, not too worried about such indirect effects here. Still, the estimated impacts include the effects of concomitant variables affected by the treatment between the age of three (when enrollment is measured) and eleven (when outcomes are measured). For example, if preschool enrollment affects children's later skill formation differently compared to family day care enrollment, this will be captured by (1).

Consider now a random coefficient model a la Björklund and Moffit (1987). Let $O^{i}$ indicate observed outcome and $X^{i}$ observable characteristics for child $i$.

$$
O^{i}=X^{i} \beta+\alpha^{i} P S^{i}+\varepsilon^{i}
$$

or alternatively

$$
O^{i}=X^{i} \beta+\alpha P S^{i}+\left[P S^{i}\left(\alpha^{i}-\bar{\alpha}\right)+\varepsilon^{i}\right]
$$

where the term in the squared brackets is the error term. Clearly, PS may be correlated with $\varepsilon$ if, for example, an omitted variable such as child quality leads to an increased likelihood of enrolling in preschool relative to family day care. Also, PS may be correlated with $\alpha$ if parents enroll children in preschool based on expected gains. For this reason, we pursue an instrumental variables strategy and exploit plausible exogenous variation in the take-up of preschool relative to family day care. In particular, we utilize the fact that some municipalities provide guaranteed access to pre-school (GAPS), should parents wish to enroll their children in this type of care, whereas others do not. We 
argue above that, conditional on observables, GAPS does not affect child outcomes and we can test whether GAPS affects the take-up of preschool.

The local average treatment effects (LATE) (Angrist, Imbens, and Rubin (1996)) is defined by the variation of the instrument that we are exploiting. Here, the LATE associated with the instrument is

$$
E\left[O_{1}-O_{0} \mid P S(G A P S)-P S(\text { no } G A P S)=1\right] \text {, }
$$

i.e. the difference in child outcome with and without pre-school exposure for the group of children who would be enrolled in pre-school if they live in a municipality that guarantees access to preschool but not otherwise. They would be children of parents who are either indifferent or are granted a slot in the non-preferred type but accepted the slot (Groups 3 and 4 in Section 3.1). Hence, these are children of parents who are truly affected by a limited supply of slots. In this sense, this is the policy relevant group. Clearly, some children may not enroll in preschool under either regime, for example, if their parents are very selective in their choice of center or, along the same lines, if one of the parents has strong preferences for staying at home. Similarly, some children may always be enrolled in preschool. This may occur by sheer luck because there is a probability that a child is always granted a slot. (They would be children of parents in Groups 1 and 2 in Section 3.1). Always- and never-takers in the terminology of Angrist, Imbens, and Rubin (1996) do not contribute with any variation and therefore do not affect the parameter estimate.

Furthermore, for the LATE presented in (1) above, we need to assume monotonicity; see Angrist, Imbens, and Rubin (1996) and Vytlacil (2002). This assumption implies that the instrument must affect individuals' behavior in one direction only. Otherwise, the estimated LATE becomes uninterpretable. Since all GAPS does is to ease access to preschool, we only expect parents to be more likely to choose preschool when exposed to the policy and not vice-versa. However, because we 
have excluded the group of parents choosing home care from our analysis, we need an extended version of monotonicity, see Froelich (2004) for intuition and Datta Gupta and Simonsen (2007) for a formal proof. In particular, we need it to be the case that

1) parents who use preschool under a GAPS regime must not use home care in the absence of GAPS,

2) parents who use preschool in the absence of GAPS must use neither family day care nor home care under a GAPS regime,

3) parents who use family day care under a GAPS regime must use neither preschool nor home care in absence of GAPS,

4) parents who use family day care in the absence of GAPS must not use home care under a GAPS regime.

This essentially corresponds to monotonicity combined with independence of irrelevant alternatives assumed in a multinomial logit model. See Datta Gupta and Simonsen (2010) who argue that it is likely to hold in our setting: firstly, because the share of children in home care only varies slightly across municipalities with and without GAPS (12 versus 16 per cent) and secondly because a Hausman-McFadden test, see Hausman and McFadden (1984), of IIA cannot reject the hypothesis that the coefficient to GAPS in the equation comparing family day care and preschool is the same in a multinomial logit including all alternatives and one in which we only include family day care and preschool (t-statistic is 0.01). Since all GAPS does is to ease access to preschool, we only worry about case 1). If it is the case, for example, that more able parents who prefer a slot in preschool choose to keep their child at home instead of sending her to family day care, we will expect the IV results to be upwards biased. See also Deaton (2010), Heckman (2010), and Imbens (2010) for a recent discussion of common threats to the validity of IV estimates. 


\section{Estimation}

We treat SDQ2007 as well as the language and cognitive test scores as continuous outcomes and model average treatment effects and local average treatment effects using 2SLS. Thus, we incorporate covariates by assuming that they enter the conditional expectation in a linear fashion and allow for heterogeneity in the effect of care holding other covariates fixed, see e.g. Angrist et al. (2000).

The remaining outcomes considered in this paper are binary in nature and this gives rise to an interesting problem when instrumenting. We know that with both a binary outcome and a binary treatment, two stage procedures where the first stage is estimated in a non-linear fashion after which the fitted values are inserted into a non-linear second stage yield inconsistent treatment effects, see e.g. Angrist (2001), Bhattacharya et al (2006), and Altonji, Elder, and Taber (2005). The reason is that such a procedure fits a misspecified model in the second stage. Also, as demonstrated in an empirical example by Altonji, Elder, and Taber (2005) and in a Monte Carlo study by Bhattacharya et al. (2006), using 2SLS often results in very imprecise and sometimes implausible estimated treatment effects in such a context. A bivariate probit, on the other hand, seems to work better, also when the data generating process is not normal, see Bhattacharya et al. (2006). Note, of course, that these conclusions and recommendations are based on the specific examples given by Altonji et al. (2005) and Bhattacharya et al. (2006). We therefore choose to implement a bivariate probit model and additionally show 2SLS results in the sensitivity analyses, see Section 5.

\section{Choice of conditioning set}

In our analysis, we condition on a rich set of variables that explains both outcomes and the choice of child care. We need information about initial conditions, determinants of earlier ability outcomes, 
and parental investments. In particular, we include information about the child measured at time of birth (birth weight, breast fed, gender, disabilities, number of siblings etc.), parents (income, labor market history, geographic location, level of education, smoking behavior, immigrant status, whether the father took leave, whether the mother experienced post-partum depression ${ }^{18}$ ), and municipalities (level of unemployment, number of immigrants, winner of most recent local government election, share of households with children out of all households in municipality). See Table B1 for a detailed description of the variables and Table B2 for means of selected variables across modes of care.

\section{Estimation results}

This section presents our estimation results. Table 4 presents regression type analyses and IV analysis exploiting GAPS. ${ }^{19}$ Remember that the results should be interpreted as the effect of enrolling in preschool at age three rather than at age four. As a point of comparison, we first show the main results (SDQ2003) from Datta Gupta and Simonsen (2010). They find that the average child benefit in terms of behavior from being enrolled in preschool relative to family day care. In line with this, the regression analyses show some positive effects of preschool enrollment relative to family day care: children in preschool do slightly better in the language test ( 0.4 points compared to a mean of about 22) and are less likely to experience delay school enrollment or progression (-4 percentage points relative to a mean of $23 \%$ ), i.e., academic redshirting seems to be less prominent for this group. Preschool children are also significantly more likely to state that they are good at most things at school (5 percentage points relative to mean of $48 \%$ ), and at math in particular (8

\footnotetext{
${ }^{18}$ Maternal mental health has been found to be significantly linked to ADHD symptoms in children (e.g. Lesesne et al. (2003)).

19 The full set of estimation results is available on request.
} 
percentage points relative to $42 \%$ ). Overall, the sizes of the effects are small relative to mean outcomes.

Regarding the IV analysis, note first that the instrument is highly significant in the first stage (OLS of take-up of pre-school on GAPS) and works in the right direction. The t-statistic clearly passes the Staiger and Stock (1997) rule of thumb that suggest that for the first stage to be sufficiently strong, the t-statistic should be above $\sqrt{10}$. Here, only the indicator for whether or not the child likes school is statistically significant and most point estimates are small. The beneficial effects on language skills, timing of school entry, and self-perceived math skills seem to be due to selection on unobservables rather than causal effects. It is, of course, not unimportant that preschool children enjoy school more but viewed broadly, there are no strong signs that preschool outperforms informal care. ${ }^{20}$ As is usual, standard errors are much larger than those of the simple regression analysis. Because of that, we cannot reject that there are some differences in outcomes between children in preschool and family day care. Note also that we are identifying off of a different population in the IV analysis, namely the group of compliers.

\footnotetext{
${ }^{20}$ There is also room for Type 1 errors when many outcomes are considered simultaneously.
} 
TABLE $4^{\mathrm{a}}$

SELECTED MARGINAL EFFECTS

MUNICIPALITY PROVIDED PRESCHOOL VERSUS FAMILY DAY CARE

\begin{tabular}{|c|c|c|c|c|c|c|c|}
\hline \multirow[t]{3}{*}{ Outcomes } & \multirow[t]{3}{*}{ Means } & \multirow[t]{3}{*}{ \# Obs } & \multirow{2}{*}{\multicolumn{2}{|c|}{$\frac{\text { Regression type analyses }}{\text { Preschool }}$}} & \multirow{2}{*}{\multicolumn{2}{|c|}{$\begin{array}{c}\text { IV analyses } \\
\text { Preschool }\end{array}$}} & \multirow{3}{*}{$\begin{array}{c}\text { t-test } \\
\text { statistic } \\
\text { equality } \\
\text { OLS vs. IV } \\
\end{array}$} \\
\hline & & & & & & & \\
\hline & & & $\begin{array}{l}\text { Marg. } \\
\text { Eff. }\end{array}$ & $\begin{array}{l}\text { Std. } \\
\text { Error }\end{array}$ & $\begin{array}{l}\text { Marg. } \\
\text { Eff. }\end{array}$ & $\begin{array}{l}\text { Std. } \\
\text { Error }\end{array}$ & \\
\hline \multicolumn{8}{|l|}{ Behavioral measure: } \\
\hline SDQ2003 & 6.55 & 4,022 & -0.421 & 0.213 & -2.533 & 1.33 & 1.568 \\
\hline SDQ2007 & 5.21 & 2,571 & -0.200 & 0.252 & -0.314 & 1.468 & 0.076 \\
\hline \multicolumn{8}{|l|}{ Objective performance measures: } \\
\hline Language test & 21.96 & 3,742 & 0.414 & 0.245 & -1.853 & 1.439 & 1.553 \\
\hline Cognitive skills test & 29.17 & 3,783 & 0.243 & 0.255 & -0.729 & 1.551 & 0.618 \\
\hline Delayed school entry (or progress) & 0.23 & 3,824 & -0.041 & 0.023 & -0.060 & 0.227 & 0.086 \\
\hline \multicolumn{8}{|l|}{ Self-evaluated school performance: } \\
\hline Excellent academic performance (0/1) & 0.36 & 3,653 & 0.001 & 0.024 & -0.053 & 0.062 & 0.808 \\
\hline Likes school very much (0/1) & 0.25 & 3,656 & 0.028 & 0.020 & 0.107 & 0.039 & -1.789 \\
\hline \multicolumn{8}{|l|}{ Strongly agree: } \\
\hline Good at most things at school (0/1) & 0.48 & 3,653 & 0.046 & 0.025 & -0.013 & 0.061 & 0.890 \\
\hline Good at math $(0 / 1)$ & 0.42 & 3,654 & 0.077 & 0.024 & -0.029 & 0.060 & 1.633 \\
\hline Good at Danish (0/1) & 0.50 & 3,653 & 0.018 & 0.025 & -0.026 & 0.060 & 0.661 \\
\hline \multicolumn{8}{|l|}{ Risky behavior measures: } \\
\hline Ever smoked (0/1) & 0.04 & 3,639 & -0.003 & 0.007 & -0.118 & 0.075 & 1.526 \\
\hline Ever drunk alcohol (0/1) & 0.08 & 3,633 & -0.010 & 0.013 & 0.001 & 0.027 & -0.375 \\
\hline Petty theft and vandalism(0/1) & 0.14 & 3,637 & 0.007 & 0.017 & -0.004 & 0.035 & 0.284 \\
\hline First stage: GAPS & & & & & 0.149 & 0.012 & \\
\hline t-statistic & & & & & 12. & & \\
\hline
\end{tabular}

${ }^{\mathrm{a}}$ Italic indicates significance at the $10 \%$ level, bold at the $5 \%$ level. Robust standard errors,

clustering at the municipality level. Models for SDQ, language and cognitive skills tests 2SLS.

Binary outcomes modeled using bivariate probits. Marginal effects evaluated at the mean.

Conditioning set described in B1. Results for SDQ2003 are taken from Datta Gupta and Simonsen (2010).

\section{Heterogeneous treatment effects and sensitivity analyses}

Effects of enrollment may vary across subpopulations. This section first shows results for each gender and next presents a set of sensitivity analyses where we exclude particular groups. We 
finally investigate the sensitivity of our results for the binary outcomes to the choice of bivariate probit model versus 2SLS.

Tables 5 and 6 give the results for boys and girls. The IV results show that preschool mainly affects boys' attitudes towards school: only preschool boys are significantly more likely to like going to school. Also, in contrast to the pooled results, preschool girls are less likely to strongly agree that they are good at most things in school. Interestingly, the estimated effect on behavior at age 11 is large and negative for boys suggesting that they benefit from being enrolled in preschool, whereas the corresponding estimate for girls is large and positive. This is in line with the results from Datta Gupta and Simonsen (2010). On the other hand, boys who have been in preschool seem significantly more likely to engage in risky behavior such as petty theft and vandalism. Unfortunately, the samples are too small to make strong conclusions across gender; some estimates become inflated but so do the standard errors. It does seem that boys are more likely to benefit from preschool relative to girls.

One might hypothesize that labor markets in larger cities are different from those of the provinces, and that this may affect child care policies as well. For example, the county of Copenhagen that includes the Danish capital and largest city with 500,000 inhabitants may be different from the rest of the country. We therefore re-estimate all models above excluding the county of Copenhagen. As seen in the first set of estimations in Table 7, all results are robust to this exclusion 
TABLE $5^{\mathrm{a}}$

SELECTED MARGINAL EFFECTS FOR BOYS

MUNICIPALITY PROVIDED PRESCHOOL VERSUS FAMILY DAY CARE

\begin{tabular}{|c|c|c|c|c|c|c|}
\hline \multirow[t]{3}{*}{ Outcomes } & \multirow[t]{3}{*}{ Means } & \multirow[t]{3}{*}{ \# Obs } & \multirow{2}{*}{\multicolumn{2}{|c|}{$\frac{\text { Regression type analyses }}{\text { Preschool }}$}} & \multirow{2}{*}{\multicolumn{2}{|c|}{$\begin{array}{c}\text { IV analyses } \\
\text { Preschool }\end{array}$}} \\
\hline & & & & & & \\
\hline & & & $\begin{array}{l}\text { Marg. } \\
\text { Eff. }\end{array}$ & $\begin{array}{l}\text { Std. } \\
\text { Error }\end{array}$ & $\begin{array}{c}\text { Marg. } \\
\text { Eff. }\end{array}$ & $\begin{array}{l}\text { Std. } \\
\text { Error }\end{array}$ \\
\hline \multicolumn{7}{|l|}{ Behavioral measure: } \\
\hline SDQ2007 & 5.63 & 1,308 & -0.307 & 0.361 & -2.845 & 1.897 \\
\hline \multicolumn{7}{|l|}{ Objective performance measures: } \\
\hline Language test & 20.50 & 1,904 & 1.027 & 0.411 & 3.431 & 2.974 \\
\hline Cognitive skills test & 28.58 & 1,925 & 0.361 & 0.439 & 0.415 & 2.380 \\
\hline Delayed school entry (or progress) & 0.33 & 1,946 & -0.056 & 0.037 & 0.064 & 0.083 \\
\hline \multicolumn{7}{|l|}{ Self-evaluated school performance: } \\
\hline Excellent academic performance (0/1) & 0.35 & 1,859 & 0.021 & 0.036 & -0.024 & 0.079 \\
\hline Likes school very much (0/1) & 0.21 & 1,861 & 0.043 & 0.027 & 0.158 & 0.048 \\
\hline \multicolumn{7}{|l|}{ Strongly agree: } \\
\hline Good at most things at school (0/1) & 0.48 & 1,859 & 0.080 & 0.039 & -0.035 & 0.078 \\
\hline Good at math (0/1) & 0.49 & 1,860 & 0.078 & 0.035 & -0.097 & 0.075 \\
\hline Good at Danish (0/1) & 0.44 & 1,859 & 0.003 & 0.038 & -0.053 & 0.083 \\
\hline \multicolumn{7}{|l|}{ Risky behavior measures: } \\
\hline Ever smoked (0/1) & 0.06 & 1,852 & -0.008 & 0.012 & -0.157 & 0.110 \\
\hline Ever drunk alcohol (0/1) & 0.12 & 1,849 & 0.013 & 0.018 & 0.022 & 0.043 \\
\hline Petty theft and vandalism (0/1) & 0.12 & 1,851 & 0.011 & 0.023 & 0.054 & 0.031 \\
\hline \multirow{2}{*}{\multicolumn{5}{|c|}{$\begin{array}{l}\text { First stage: GAPS } \\
\text { t-statistic }\end{array}$}} & 0.121 & 0.03 \\
\hline & & & & & \multicolumn{2}{|c|}{4.033} \\
\hline
\end{tabular}

${ }^{a}$ Italic indicates significance at the $10 \%$ level, bold at the $5 \%$ level. Robust standard errors, clustering at the municipality level. Models for SDQ, language and cognitive skills tests 2SLS. Binary outcomes modeled using bivariate probits. Marginal effects evaluated at the mean. Conditioning set described in B1 
TABLE $6^{\mathrm{a}}$

SELECTED MARGINAL EFFECTS FOR GIRLS

MUNICIPALITY PROVIDED PRESCHOOL VERSUS FAMILY DAY CARE

\begin{tabular}{|c|c|c|c|c|c|c|}
\hline \multirow[t]{3}{*}{ Outcomes } & \multirow[t]{3}{*}{ Means } & \multirow[t]{3}{*}{ \# Obs } & \multirow{2}{*}{\multicolumn{2}{|c|}{$\frac{\text { Regression type analyses }}{\text { Preschool }}$}} & \multirow{2}{*}{\multicolumn{2}{|c|}{$\begin{array}{c}\text { IV analyses } \\
\text { Preschool }\end{array}$}} \\
\hline & & & & & & \\
\hline & & & $\begin{array}{l}\text { Marg. } \\
\text { Eff. }\end{array}$ & $\begin{array}{l}\text { Std. } \\
\text { Error }\end{array}$ & $\begin{array}{c}\text { Marg. } \\
\text { Eff. }\end{array}$ & $\begin{array}{l}\text { Std. } \\
\text { Error }\end{array}$ \\
\hline \multicolumn{7}{|l|}{ Behavioral measure: } \\
\hline SDQ2007 & 4.78 & 1,263 & -0.005 & 0.327 & 3.041 & 2.199 \\
\hline \multicolumn{7}{|l|}{ Objective performance measures: } \\
\hline Language test & 21.62 & 1,838 & -0.073 & 0.344 & 0.163 & 1.968 \\
\hline Cognitive skills test & 29.79 & 1,858 & 0.118 & 0.333 & -1.019 & 2.031 \\
\hline Delayed school entry (or progress) & 0.12 & 1,878 & -0.016 & 0.021 & -0.053 & 0.067 \\
\hline \multicolumn{7}{|l|}{ Self-evaluated school performance: } \\
\hline Excellent academic performance (0/1) & 0.37 & 1,794 & -0.021 & 0.031 & -0.111 & 0.097 \\
\hline Likes schoolvery much (0/1) & 0.29 & 1,795 & 0.009 & 0.028 & 0.051 & 0.092 \\
\hline \multicolumn{7}{|l|}{ Strongly agree: } \\
\hline Good at most things at school (0/1) & 0.48 & 1,795 & 0.019 & 0.034 & -0.019 & 0.086 \\
\hline Good at math (0/1) & 0.33 & 1,795 & 0.067 & 0.030 & 0.012 & 0.082 \\
\hline Good at Danish (0/1) & 0.57 & 1,797 & 0.033 & 0.034 & 0.007 & 0.093 \\
\hline \multicolumn{7}{|l|}{ Risky behavior measures: } \\
\hline Ever smoked (0/1) & 0.03 & 1,787 & 0.002 & 0.006 & -0.017 & 0.057 \\
\hline Ever drunk alcohol (0/1) & 0.04 & 1,784 & -0.028 & 0.014 & -0.014 & 0.034 \\
\hline Petty theft and vandalism(0/1) & 0.12 & 1,786 & -0.002 & 0.021 & -0.125 & 0.093 \\
\hline \multirow{2}{*}{\multicolumn{5}{|c|}{$\begin{array}{l}\text { First stage: GAPS } \\
\text { t-statistic }\end{array}$}} & 0.150 & 0.028 \\
\hline & & & & & \multicolumn{2}{|c|}{5.357} \\
\hline
\end{tabular}

${ }^{a}$ Italic indicates significance at the $10 \%$ level, bold at the $5 \%$ level. Robust standard errors, clustering at the municipality level. Models for SDQ, language and cognitive skills tests 2SLS. Binary outcomes modeled using bivariate probits. Marginal effects evaluated at the mean. Conditioning set described in B1. 
TABLE $7^{\mathrm{a}}$

SELECTED MARGINAL EFFECTS, SENSITIVITY ANALYSES

MUNICIPALITY PROVIDED PRESCHOOL VERSUS FAMILY DAY CARE

\begin{tabular}{|c|c|c|c|c|c|c|c|c|c|c|c|c|}
\hline \multirow{3}{*}{ Outcomes } & \multicolumn{4}{|c|}{$\begin{array}{l}\text { Exclude Copenhagen } \\
\text { (\# obs left 2,425) }\end{array}$} & \multicolumn{4}{|c|}{$\begin{array}{l}\text { Exclude weak children } \\
\text { (\# obs left } 1,080)\end{array}$} & \multicolumn{4}{|c|}{$\begin{array}{l}\text { Exclude children with siblings } \\
\text { aged } 4-6 \text { (\# obs left 1,788) }\end{array}$} \\
\hline & \multicolumn{2}{|c|}{$\begin{array}{c}\text { Regression type } \\
\text { analyses } \\
\text { Preschool }\end{array}$} & \multicolumn{2}{|c|}{$\begin{array}{c}\text { IV } \\
\text { analyses } \\
\text { Preschool }\end{array}$} & \multicolumn{2}{|c|}{$\begin{array}{c}\text { Regression type } \\
\text { analyses } \\
\text { Preschool }\end{array}$} & \multicolumn{2}{|c|}{$\begin{array}{c}\text { IV } \\
\text { analyses } \\
\text { Preschool }\end{array}$} & \multicolumn{2}{|c|}{$\begin{array}{c}\text { Regression type } \\
\text { analyses } \\
\text { Preschool }\end{array}$} & \multicolumn{2}{|c|}{$\begin{array}{c}\text { IV } \\
\text { analyses } \\
\text { Preschool }\end{array}$} \\
\hline & $\begin{array}{c}\text { Marg. } \\
\text { Eff. }\end{array}$ & $\begin{array}{c}\text { Std. } \\
\text { Error }\end{array}$ & $\begin{array}{c}\text { Marg. } \\
\text { Eff. }\end{array}$ & $\begin{array}{c}\text { Std. } \\
\text { Error }\end{array}$ & $\begin{array}{c}\text { Marg. } \\
\text { Eff. }\end{array}$ & $\begin{array}{c}\text { Std. } \\
\text { Error }\end{array}$ & $\begin{array}{c}\text { Marg. } \\
\text { Eff. }\end{array}$ & $\begin{array}{c}\text { Std. } \\
\text { Error }\end{array}$ & $\begin{array}{c}\text { Marg. } \\
\text { Eff. }\end{array}$ & $\begin{array}{c}\text { Std. } \\
\text { Error } \\
\end{array}$ & $\begin{array}{c}\text { Marg. } \\
\text { Eff. }\end{array}$ & $\begin{array}{c}\text { Std. } \\
\text { Error } \\
\end{array}$ \\
\hline \multicolumn{13}{|l|}{ Behavioral measure: } \\
\hline SDQ2007 & -0.230 & 0.257 & -0.235 & 1.446 & -0.509 & 0.371 & -2.771 & 1.913 & -0.582 & 0.304 & -0.532 & 1.811 \\
\hline \multicolumn{13}{|l|}{ Objective performance measures: } \\
\hline Language test & 0.397 & 0.259 & -1.441 & 1.848 & 0.223 & 0.373 & -1.374 & 2.072 & 0.573 & 0.320 & -0.996 & 2.144 \\
\hline Cognitive skills test & 0.333 & 0.249 & -0.130 & 1.549 & -0.293 & 0.367 & -1.702 & 2.088 & 0.383 & 0.272 & 1.518 & 1.834 \\
\hline Delayed school entry (or progress) & -0.046 & 0.024 & -0.056 & 0.053 & -0.021 & 0.028 & -0.005 & 0.091 & -0.084 & 0.029 & -0.019 & 0.058 \\
\hline \multicolumn{13}{|l|}{ Self-evaluated school performance: } \\
\hline Excellent academic performance (0/1) & 0.001 & 0.025 & -0.050 & 0.063 & -0.008 & 0.040 & -0.022 & 0.098 & 0.005 & 0.030 & -0.108 & 0.077 \\
\hline Likes school very much $(0 / 1)$ & 0.024 & 0.021 & 0.096 & 0.040 & 0.008 & 0.033 & 0.131 & 0.051 & 0.045 & 0.024 & 0.112 & 0.049 \\
\hline \multicolumn{13}{|l|}{ Strongly agree: } \\
\hline Good at most things at school (0/1) & 0.045 & 0.027 & -0.020 & 0.064 & 0.072 & 0.038 & 0.051 & 0.089 & 0.053 & 0.030 & -0.041 & 0.082 \\
\hline Good at math $(0 / 1)$ & 0.080 & 0.025 & -0.035 & 0.056 & 0.043 & 0.040 & -0.034 & 0.085 & 0.079 & 0.028 & -0.069 & 0.076 \\
\hline Good at Danish (0/1) & 0.022 & 0.026 & -0.016 & 0.069 & 0.053 & 0.038 & 0.097 & 0.086 & 0.024 & 0.030 & -0.074 & 0.074 \\
\hline \multicolumn{13}{|l|}{ Risky behavior measures: } \\
\hline Ever smoked (0/1) & -0.003 & 0.006 & -0.135 & 0.084 & 0.001 & 0.010 & -0.269 & 0.041 & -0.003 & 0.007 & -0.100 & 0.088 \\
\hline Ever drunk alcohol (0/1) & -0.012 & 0.012 & -0.005 & 0.027 & 0.018 & 0.011 & -0.025 & 0.059 & -0.007 & 0.015 & 0.027 & 0.015 \\
\hline Petty theft and vandalism $(0 / 1)$ & 0.005 & 0.016 & -0.017 & 0.036 & 0.035 & 0.022 & -0.013 & 0.052 & 0.013 & 0.018 & -0.021 & 0.048 \\
\hline First stage: GAPS & & & 0.134 & 0.027 & & & 0.148 & 0.033 & & & 0.128 & 0.027 \\
\hline t-statistic & & \multicolumn{3}{|c|}{4.963} & \multicolumn{4}{|c|}{4.485} & & & \multicolumn{2}{|c|}{4.741} \\
\hline
\end{tabular}

${ }^{\mathrm{a}}$ Italic indicates significance at the $10 \%$ level and bold at the $5 \%$ level. Robust standard errors, clustering at the municipality level. \# obs refers to SDQ model. Conditioning set described in Table B1. 
TABLE $8^{\mathbf{a}}$

SELECTED MARGINAL EFFECTS

MUNICIPALITY PROVIDED PRESCHOOL VERSUS FAMILY DAY CARE

\begin{tabular}{|c|c|c|c|c|c|c|}
\hline \multirow[t]{3}{*}{ Outcomes } & \multirow[t]{3}{*}{ Means } & \multirow[t]{3}{*}{ \# Obs } & \multirow{2}{*}{\multicolumn{2}{|c|}{$\begin{array}{l}\text { IV analyses } \\
\text { 2SLS } \\
\text { Preschool }\end{array}$}} & \multirow{2}{*}{\multicolumn{2}{|c|}{$\begin{array}{c}\begin{array}{c}\text { IV analyses } \\
\text { Bivariate probits }\end{array} \\
\text { Preschool }\end{array}$}} \\
\hline & & & & & & \\
\hline & & & $\begin{array}{c}\text { Marg. } \\
\text { Eff. }\end{array}$ & $\begin{array}{l}\text { Std. } \\
\text { Error }\end{array}$ & $\begin{array}{c}\text { Marg. } \\
\text { Eff. }\end{array}$ & $\begin{array}{c}\text { Std. } \\
\text { Error } \\
\end{array}$ \\
\hline \multicolumn{7}{|l|}{ Objective performance measures: } \\
\hline Delayed school entry (or progress) & 0.23 & 3,824 & -0.058 & 0.138 & -0.060 & 0.227 \\
\hline \multicolumn{7}{|l|}{ Self-evaluated school performance: } \\
\hline Excellent academic performance (0/1) & 0.36 & 3,653 & -0.146 & 0.142 & -0.053 & 0.062 \\
\hline Likes school very much $(0 / 1)$ & 0.25 & 3,656 & 0.008 & 0.123 & 0.107 & 0.039 \\
\hline \multicolumn{7}{|l|}{ Strongly agree: } \\
\hline Good at most things at school (0/1) & 0.48 & 3,653 & -0.072 & 0.156 & -0.013 & 0.061 \\
\hline Good at math $(0 / 1)$ & 0.42 & 3,654 & -0.277 & 0.144 & -0.029 & 0.060 \\
\hline Good at Danish (0/1) & 0.50 & 3,653 & -0.098 & 0.173 & -0.026 & 0.060 \\
\hline \multicolumn{7}{|l|}{ Risky behavior measures: } \\
\hline Ever smoked (0/1) & 0.04 & 3,639 & -0.084 & 0.055 & -0.118 & 0.075 \\
\hline Ever drunk alcohol (0/1) & 0.08 & 3,633 & -0.059 & 0.078 & 0.001 & 0.027 \\
\hline Petty theft and vandalism (0/1) & 0.14 & 3,637 & -0.036 & 0.017 & -0.004 & 0.035 \\
\hline
\end{tabular}

${ }^{\mathrm{a}}$ Italic indicates significance at the 10\% level and bold at the 5\% level. Robust standard errors, clustering at the municipality level. Conditioning set described in Table B1.

The second set of estimations in Table 7 shows the results from dropping particularly disadvantaged children from the sample: children who have not been breast fed, children who have low birth weight, children who are physically disabled, immigrants and children brought up in single parent households affects significance but renders our results largely unchanged. The only major change is that preschool has a significantly reducing effect on smoking for the more advantaged group.

Since having older siblings (aged 4-6) enrolled in care allows a younger child to jump waiting lists, and one may worry that conditioning on sibling information does not sufficiently account for this, we exclude the part of the sample with siblings in the 4-6 age range. The third section in Table 7 
presents the results. Again, parameter estimates are robust, though levels of significance are affected slightly because the sample is reduced considerably.

Finally, Table 8 investigates whether our IV results are robust to choosing a 2SLS procedure over a bivariate probit for binary outcomes. As argued above, the latter is more appropriate. Table 8 demonstrates that 2SLS estimates are generally more negative than those from the bivariate probits of Table 4 but the standard errors are also larger. In fact, none of the estimates in Table 8 are significantly different across model type.

\section{Conclusion}

This paper contributes with rare evidence on the effects of modes of early child care given that a child is placed in non-parental care. Specifically, we investigate whether children benefit from being enrolled for roughly an extra year in preschool at age three relative to non-center-based care in a regime with universal access to care. Outcomes are measured at age eleven and include both objective and self-reported measures of cognitive and non-cognitive skills as well as risky behavior such as smoking, drinking, petty theft and vandalism. We use a longitudinal survey of children born in 1995 that is linked to administrative registers and exploit plausible exogenous variation in the take-up of preschool for identification purposes. Our instrument is a policy that guarantees access to preschool. We therefore estimate a local average treatment effect of the effect of preschool relative to non-center-based care for the group of children whose parents choose preschool when there is unlimited access but not otherwise.

We find no strong evidence that one type of non-parental care outperforms the other. Children put in preschool from an early age appear to do just as well as children looked after in smaller, more 
informal non-center-based settings in terms of objective academic performance, self-evaluated school performance, overall behavior and engagement in risky health behaviors and petty crime, all measured at the age of $11 .^{21}$ This is rather different from some of the evidence from e.g. the US and Canada that showed deleterious short run effects of institutionalized childcare for children under 3 in terms of increased aggression and disobedience. The only significant result is that children enrolled in preschool at age three seem to like school more than their counterparts in informal care - and this tendency is particularly strong for boys.

The findings from Datta Gupta and Simonsen (2010) that short term behavior was significantly positively affected by preschool enrollment relative to family day care enrollment could be a result of earlier socialization of preschool children which is reflected in their greater emotional and social competence at school-entering age, but there is no significant gap by age eleven. By that age, most children have been enrolled in public schools and made use of common after-school programs, and the exposure to a wide spectrum of peers from different family backgrounds may tend to reduce the variance of skills in the long-run (Esping-Andersen (2006)). The literature investigating effects of early (Kindergarten) classroom and teacher characteristics may also aid our understanding of this result: here it is typically found that teacher experience but not degree impact on child outcomes (e.g. Krueger (1999) and Chetty et al. (2010)) and that smaller class size ${ }^{22}$ is preferable both in the

\footnotetext{
${ }^{21}$ As is usual, however, standard errors from the IV analysis are large. Because of that, we cannot reject that there are some differences in outcomes between children in preschool and family day care.

${ }^{22}$ In the STAR Project analyzed in Krueger (1999) and Chetty et al. (2010), class sizes of on average 15 students were compared to class sizes of roughly 22 students. This is clearly a different margin than the one we consider in this paper.
} 
short and very long run. Given these results, it is not ex ante obvious which type of non-parental care is the better option. Whether there will be longer run effects of type of non-parental childcare remains an open question. Several papers find long-term effects of early interventions despite a fade out in the medium term (e.g. Chetty et al. (2010) for the STAR project, Heckman et al. (2010) for the Perry Preschool Project, and Currie and Thomas (1995) for the Head Start Program), though this is argued to be because of persistent effects on behavior, which we do not find much evidence of in this paper.

Of course, one could argue that Danish child care is universal, highly regulated and of relatively high quality, at least in terms of staff per child, and as such not representative of preschool elsewhere. Yet universal publicly subsidized child care effective in e.g. the Nordic countries is an important policy on the political agenda in many countries. Universal care was recently introduced in Quebec, Canada, and similar programs are in place in the US states of Georgia, New York, and Oklahoma. The European Union is also pushing for increases in access to child care among its member countries. The Nordic countries, in our case Denmark, provide a unique laboratory in which one can evaluate the effects, not only of the introduction of such a regime as in Havnes and Mogstad (forthcoming) but also of an established version of universal care. Furthermore, one can think of our estimates as upper bounds on the effects of preschool relative to (regulated) non-centerbased care in a setting with universal care: if relatively high quality preschool does not matter much for child outcomes compared to informal non-center-based care, there is no reason to expect lower quality preschool to improve on child outcomes either, given the same quality of non-center based care. 
Given the limited work in this area, more work is clearly needed. In particular, it would be interesting to explore the extent of heterogeneity in effects using larger samples than the one available in this paper.

\section{References}

Almond, D. and J. Currie (forthcoming), 'Human Capital Development Before Five’ in Handbook of Labor Economics, David Card and Orley Ashenfelter (eds.)

Altonji, J. G., T. E. Elder, C. R. Taber (2005), 'An Evaluation of Instrumental Variable Strategies for Estimating the Effects of Catholic Schooling, Journal of Human Resources 40, 791-821.

Angrist, J. D. (2001), 'Estimation of Limited Dependent Variable Models with Dummy Endogenous Regressors: Simple Strategies for Empirical Practice, Journal of Business and Economic Statistics 19, 2-16.

Angrist, J. D., K. Graddy, and G. W. Imbens (2000), 'The Interpretation of Instrumental Variables Estimators in Simultaneous Equations Models with and Application to the Demand for Fish', Review of Economic Studies 67, 499-527.

Angrist, J. D., G. W. Imbens, and D. B. Rubin (1996), 'Identification of Causal Effects Using Instrumental Variables', Journal of the American Statistical Association 91, 444-455.

Baker, M., J. Gruber, and K. Milligan (forthcoming): ‘Universal Childcare, Maternal Labor Supply and Family Well-being', Journal of Political Economy.

Bhattacharya, J., D. Goldman, and D. McCaffrey (2006), 'Estimating Probit Models with SelfSelected Treatments', Statistics in Medicine 25, 389-413.

Belsky, J., D.L. Vandell, M. Burchinal, A.K. Clarke-Stewart, K. McCartney, M.T. Owen and the NICHD Early Child Care Research Network (2007): ‘Are Their Long-Term Effects of Early Child Care?’, Child Development 78, Issue 2, 681-701. 
Bernal, R. and M. Keane (2008): Child Care Choices and Children’s Cognitive Achievement: The Case of Single Mothers’, mimeo, Universidad de los Andes.

Björklund and Moffit (1987), 'The Estimation of Wage Gains and Welfare Gains in Self-Selection Models', The Review of Economics and Statistics 69, 42-49.

Blau, D. and J. Currie (2006), 'Who is Minding the Kids', The Handbook of Education Economics, F. Welch and E. Hanushek eds, New York: North Holland.

Carneiro, P. and R. Ginja (2008), 'Preventing Behavior Problems in Childhood and Adolescence:

Evidence from Head Start', mimeo University College London.

Chetty, R., J. N. Friedman, N. Hilger, E. Saez, D. W. Schanzenbach and D. Yagan (2010), 'How Does Kindergarten Classroom Affect Your Earnings? Evidence from Project Star’, NBER working paper \# 16381.

Cunha, F. and J. Heckman (2008), 'Formulating, Identifying, and Estimating the Technology of Cognitive and Non-cognitive Skill Formation', Journal of Human Resources 43, 738-782.

Currie, J. (2001), 'Early Childhood Intervention Programs: What Do We Know?', Journal of Economic Perspectives 15, 213-239.

Currie, J. (1994). 'Welfare and the Well-being of Children: The Relative Effectiveness of Cash and in-kind Transfers’, in James M. Poterba eds, Tax Policy and the Economy Vol. 8, MIT Press.

Currie, J. and D. Thomas (1995), 'Does Head Start Make a Difference?’, The American Economic Review 85, 341-364.

Currie, J. and D. Thomas (1999), 'Does Head Start Help Hispanic Children?', Journal of Public Economics 74, 235-262.

Currie, J., E. Garces, and D. Thomas (2002), 'Longer Term Effects of Head Start', The American Economic Review 92, 999-1012. 
Datta Gupta, N. and M. Simonsen (2010), ‘Non-cognitive Child Outcomes and Universal High Quality Child Care', Journal of Public Economics 94, 30-43.

Deaton, A. (2010), 'Instruments, Randomization, and Learning about Development', Journal of Economic Literature 48, 424-455.

Elder, T. E. and D. H. Lubotsky (2009), 'Kindergarten Entrance Age and Children’s Achievement’, Journal of Human Resources 44, 641-683.

Esping-Andersen, G. (2006). 'Families, Government and the Distribution of Skills', mimeo, Universitat Pompeu Fabra.

Goodman, R. (1997), ‘The Strengths and Difficulties Questionnaire: A Research Note.’ Journal of Child Psychology and Psychiatry 38, 581-586.

Grönquist, E., B. Öckert and J. Vlachos (2010), 'The Intergenerational Transmission of Cognitive and Non-cognitive Abilities, CEPR DP 7908.

Havnes, T. and M. Mogstad (forthcoming), 'No Child Left Behind: Subsidized Child Care and Children’s Long-Run Outcomes, American Economic Journal: Economic Policy.

Hawes, D. J. and M. R. Dadds (2004), 'Australian Data and Psychometric Properties of the Strenghts and Difficulties Questionnaire', Australian and New Zealand Journal of Psychiatry 38, 644-651.

Heckman, J. J (2010), 'Building Bridges between Structural and Program Evaluation Approaches to Evaluating Policy’, Journal of Economic Literature 48, 356-398.

Heckman, J. J., S. H. Moon, R. Pinto, P. Savelyev and A. Yavitz (2010), 'The Rate of Return to the High Scope Perry Preschool Program’ Journal of Public Economics 94, 114-128.

Heckman, J. J. (2008), ‘Schools, Skills, and Synapses’, NBER working paper \# 14064.

Heckman, J. J. and D. Masterov (2007), 'The Productivity Argument for Investing in Young Children’, NBER working paper \# 13016. 
Imbens, G. (2010), 'Better LATE than Nothing: Some Comments on Deaton (2009) and Heckman and Urzua (2009)', Journal of Economic Literature 48, 399-423.

Klasen H., W. Woerner, D. Wolke, R. Meyer, S. Overmeyer, W. Kaschnitz, A. Rothenberger and R. Goodman, (2000). 'Comparing the German Versions of the Strengths and Difficulties Questionnaire (SDQ-Deu) and the Child Behavior Checklist.' European Child \& Adolescent Psychiatry 9, 271276.

Koskelainen, M., A. Sourander and A. Kaljonen, (2000). 'The Strengths and Difficulties Questionnaire among Finnish School-aged Children and Adolescents.' European Child \& Adolescent Psychiatry 9, 277-284.

Lesesne, C.N., Vissner, S.N., and C.P. White (2003), 'Attention-Deficit/Hyperactivity Disorder in School-Aged Children: Association with Maternal Mental Health and Use of Health Care Resources’, Pediatrics 111, 1232-1237.

Magnuson, K. A., C. Ruhm, and J. Waldfogel (2007), 'Does Prekindergarten Improve School Preparation and Performance?', Economics of Education Review 26, 33-51.

Mathai, J., P. Anderson and A. Bourne, (2002). 'The Strengths and Difficulties Questionnaire (SDQ) as a screening measure prior to admission to a Child and Adolescent Mental Health Service (CAMHS).' Australian e-Journal for the Advancement of Mental Health 1, 1-12.

Simonsen, M. (2010), 'Price of High Quality Child Care and Female Employment', Scandinavian Journal of Economics 112, 570-594.

Staiger, D. and J. H. Stock (1997), 'Instrumental Variables Regression with Weak Instruments', Econometrica 65, 557-586.

Stipek, D. J., R. Feiler, P. Byler, R. Ryan, S. Milburn, and J. M. Salmon (1998), 'Good Beginnings: What Difference Does the Program Make in Preparing Young Children for School?', Journal of Applied Developmental Psychology 19, 41-66. 
Woerner W., A. Becker and A. Rothenberger (2004), 'Normative Data and Scale Properties of the German Parent SDQ’ European Child \& Adolescent Psychiatry 13, ii3-ii10.

\section{Appendix A}

As in almost all surveys, there is significant attrition in the data. ${ }^{23}$ Table A1 shows attrition patterns. We analyze SDQ since this is the outcome observed in both 2003 and 2007. On average 36\% of the families surveyed in 2003, where the first set of child outcomes is observed, are not re-interviewed in 2007. Attrition is similar in family day care and preschool.

TABLE A1 ${ }^{\text {a }}$

DATA ATTRITION

\begin{tabular}{lcccccc}
\hline & & \multicolumn{3}{c}{ \# obs } & \#obs 2007/ \\
& SDQ2003 & SDQ2007 & Only SDQ2003 & Only SDQ2007 & Both & \#obs 2003 \\
\hline Family day care & 806 & 533 & 293 & 20 & 513 & 0.66 \\
Preschool & 3237 & 2038 & 1301 & 102 & 1936 & 0.63 \\
\hline
\end{tabular}

${ }^{\text {a }}$ Source: Own calculations, data used in empirical analyses

Table A2 first presents mean SDQ2003 for the 2003 and 2007 sample. First note that SDQ2003 is significantly lower for the 2007 sample compared to the 2003 sample. This suggests that it is the high-SDQ children who leave the sample. ${ }^{24}$ Table A2 next presents mean SDQ2003 and SDQ2007

\footnotetext{
${ }^{23}$ In Belsky et al. (2007), who use longitudinal data to investigate the effects of early day care on outcomes measured at age twelve, only 293 out of 1,364 families (22\%) has complete data on all predictors and outcomes. In Magnuson, Ruhm, and Waldfogel (2006), who consider the effects of prekindergarten on school readiness, 7,388 out of 17,612 children (58\%) have complete data.

${ }^{24}$ Another way of seeing this is by running a probit using an attrition indicator as outcome variable. Here we see that both mother's length of education and labor market experience decrease attrition. Similarly, children with low birth weight born to single mothers who smoke are more likely attrit.
} 
for the 2007 sample. In general, children become better behaved over time. This was also demonstrated in Figure 2 above. Still, we observe that children in family day care and preschool experience similar changes in behavior.

TABLE A2 ${ }^{\mathrm{a}}$

DATA ATTRITION AND SDQ

\begin{tabular}{lcccccc}
\hline & \multicolumn{2}{c}{ SDQ2003 } & & \multicolumn{3}{c}{ 2007 sample } \\
& 2003 sample & 2007 sample & Difference & SDQ2003 & SDQ2007 & Difference \\
\hline Family day care & 6.79 & 6.25 & $\mathbf{- 0 . 5 4}$ & 6.25 & 5.27 & $\mathbf{- 0 . 9 8}$ \\
& $(5.19)$ & $(4.85)$ & & $(4.84)$ & $(4.42)$ & \\
\multirow{2}{*}{ Preschool } & 6.49 & 6.15 & $\mathbf{- 0 . 3 4}$ & 6.15 & 5.13 & $\mathbf{- 1 . 0 2}$ \\
& $(5.04)$ & $(4.75)$ & & $(4.75)$ & $(4.50)$ & \\
\hline
\end{tabular}

${ }^{a}$ Bold indicated significance the 5\% level.

Table A3 compares the regression and IV results with SDQ2003 as outcome using the full and the reduced sample. The estimates from the full and reduced samples are not significantly different from each other.

TABLE A3 ${ }^{\mathrm{a}}$

SELECTED OLS AND IV ESTIMATES

MUNICIPALITY PROVIDED PRESCHOOL VERSUS FAMILY DAY CARE

\begin{tabular}{lcccc}
\hline Outcome & \multicolumn{2}{c}{ Full set of obs } & \multicolumn{2}{c}{ Attrited sample } \\
\cline { 2 - 5 } & \multicolumn{2}{c}{ Preschool } & \multicolumn{2}{c}{ Preschool } \\
& Marg. & Std. & Marg. & Std. \\
& Eff. & Error & Eff. & Error \\
\hline SDQ2003 & & & & \\
OLS & $\mathbf{- 0 . 4 2 1}$ & 0.213 & -0.164 & 0.240 \\
IV & -2.533 & 1.330 & -2.629 & 1.709 \\
\hline
\end{tabular}

${ }^{a}$ Italic indicates significance at the $10 \%$ level and bold at the $5 \%$ level. Robust standard errors, clustering at the municipality level. Conditioning set described in Table B1

\section{Appendix B}

This appendix shows details about the conditioning set. 
TABLE B1

\section{DETAILED DESCRIPTION OF VARIABLES}

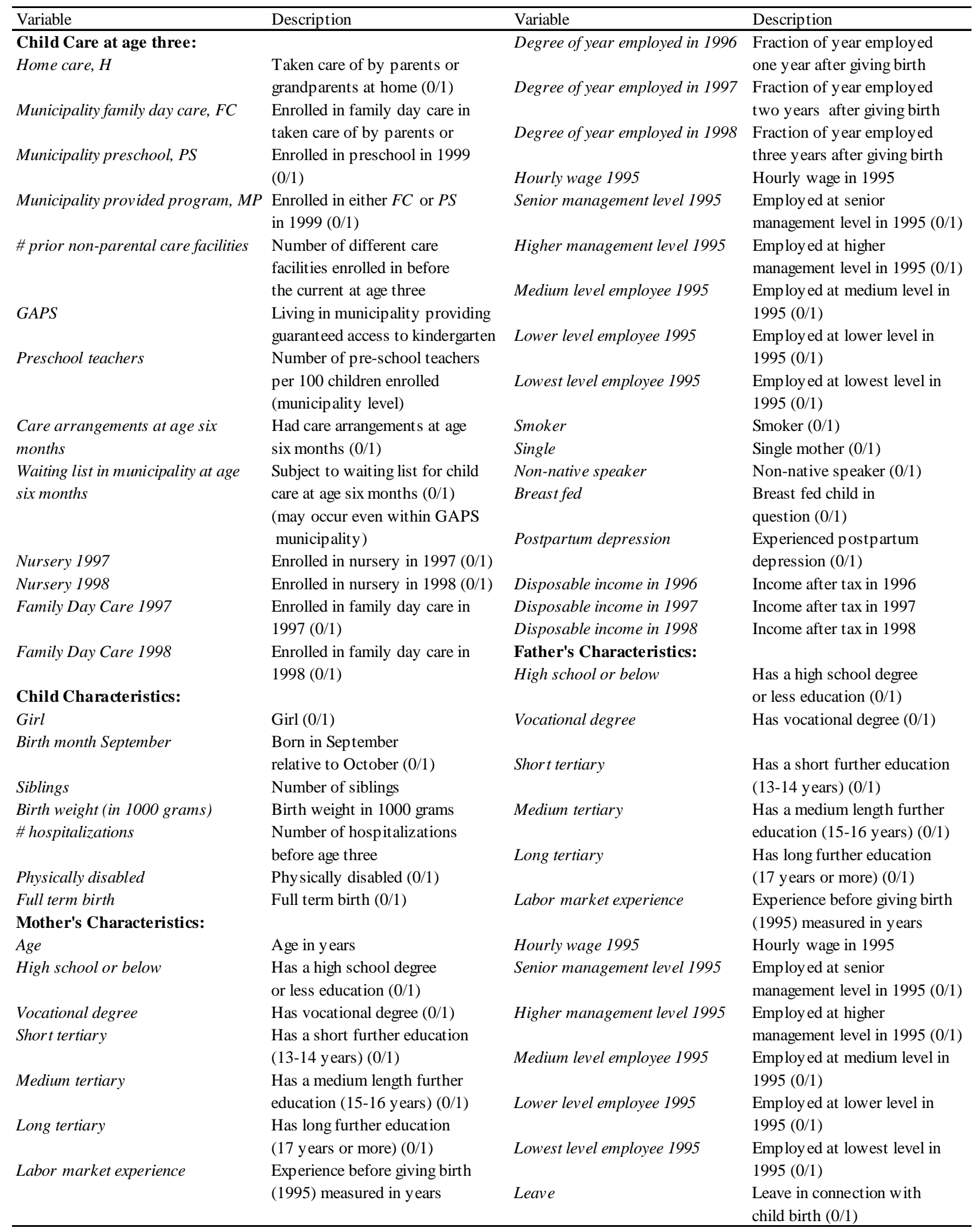


TABLE B1 CONTINUED

\section{DETAILED DESCRIPTION OF VARIABLES}

\begin{tabular}{|c|c|c|c|}
\hline Variable & Description & Variable & Description \\
\hline \multicolumn{2}{|c|}{ Municipality and Regional Characteristics: } & Unemployment rate & Share of unemployed among \\
\hline \multirow[t]{2}{*}{ Region 1} & Residing in county of & & women in municipality, 16-49 \\
\hline & Copenhagen, 1999 (0/1) & & years of age, 1999 \\
\hline \multirow[t]{3}{*}{ Region 2} & Residing in counties of & Single parent children & Share of single parent \\
\hline & Frederiksborg and & & children 0-17 y ears old in \\
\hline & Roskilde, 1999 (0/1) & & municpality, 1999 \\
\hline \multirow[t]{3}{*}{ Region 3} & Residing in counties of & Asylum seekers & \# of asylum seekers per \\
\hline & Western Sealand and & & 10,000 inhabitants in \\
\hline & Storstrøm, $1999(0 / 1)$ & & municipality, 1999 \\
\hline \multirow[t]{2}{*}{ Region 4} & Residing in county of & Third world immigrants & \# of third world immigrants \\
\hline & Fuen, $1999(0 / 1)$ & & per 10,000 inhabitants in \\
\hline \multirow[t]{3}{*}{ Region 5} & Residing in counties of & & municipality, 1999 \\
\hline & Southern Jutland and & Social Democrats & Largest party in 1997 \\
\hline & Ribe, 1999 (0/1) & & municipality election \\
\hline \multirow[t]{3}{*}{ Region 6} & Residing in counties of & & social democrats $(0 / 1)$ \\
\hline & Vejle and Ringkøbing, & Conservatives & Largest party in 1997 \\
\hline & $1999(0 / 1)$ & & municipality election \\
\hline \multirow[t]{3}{*}{ Region 7} & Residing in counties of & & conservatives $(0 / 1)$ \\
\hline & Aarhus and Viborg, 1999 & Liberals & Largest party in 1997 \\
\hline & $(0 / 1)$ & & municipality election \\
\hline \multirow[t]{2}{*}{ Region 8} & Residing in county of & & liberals $(0 / 1)$ \\
\hline & Northern Jutland, 1999 (0/1) & Child families & $\begin{array}{l}\text { Share of families with children } \\
\text { among all households within } \\
\text { municipality }\end{array}$ \\
\hline
\end{tabular}

TABLE B2 ${ }^{\mathrm{a}}$

MEANS OF SELECTED VARIABLES BY MODE OF CARE

\begin{tabular}{lcccc}
\hline & \multicolumn{2}{c}{ Preschool } & \multicolumn{2}{c}{ Family Day Care } \\
& Mean & Std. Dev. & Mean & Std. Dev. \\
\hline Child Care at age three: & & & & \\
Hours in non-parental care & 33.02 & 7.14 & $\mathbf{3 4 . 3 7}$ & 7.21 \\
\# prior non-parental care facilities & 2.75 & 0.80 & $\mathbf{1 . 9 5}$ & 0.71 \\
Preschool teachers & 17.23 & 2.57 & $\mathbf{1 6 . 7 5}$ & 3.54 \\
Arranged for care at age six months & 0.32 & 0.47 & 0.34 & 0.47 \\
Waiting list in munipality at age six months & 0.22 & 0.41 & 0.20 & 0.40 \\
Child Characteristics: & & & & \\
Girl & 0.48 & 0.50 & 0.49 & 0.50 \\
Birth month September & 0.39 & 0.49 & $\mathbf{0 . 3 4}$ & 0.47 \\
Siblings & 0.77 & 0.83 & 0.81 & 0.85 \\
Birth weight (in 1000 grams) & 3.50 & 0.60 & 3.53 & 0.58 \\
\# hospitalizations & 0.88 & 0.32 & $\mathbf{0 . 9 1}$ & 0.28 \\
Physically disabled & 0.04 & 0.19 & 0.04 & 0.20 \\
Full term birth & 0.45 & 0.50 & 0.46 & 0.50 \\
\hline
\end{tabular}

${ }^{a}$ Bold numbers indicate that means for family day care children are significantly different from those in preschool (5 \% level) 
TABLE B2 CONTINUED ${ }^{\mathrm{a}}$

MEANS OF SELECTED VARIABLES BY MODE OF CARE

\begin{tabular}{|c|c|c|c|c|}
\hline & \multicolumn{2}{|c|}{ Preschool } & \multicolumn{2}{|c|}{ Family Day Care } \\
\hline & Mean & Std. Dev. & Mean & Std. Dev. \\
\hline \multicolumn{5}{|l|}{ Mother's Characteristics: } \\
\hline Age & 28.37 & 4.61 & 28.23 & 4.34 \\
\hline High School or below & 0.33 & & 0.33 & \\
\hline Vocational degree & 0.37 & 0.48 & 0.42 & 0.49 \\
\hline Short further & 0.23 & 0.42 & 0.20 & 0.40 \\
\hline Long further & 0.07 & 0.26 & 0.05 & 0.21 \\
\hline Labor market experience & 7.37 & 5.81 & 7.15 & 5.50 \\
\hline Degree of year employed in 1996 & 0.55 & 0.35 & 0.57 & 0.34 \\
\hline Degree of year employed in 1997 & 0.64 & 0.40 & 0.65 & 0.39 \\
\hline Degree ofyear employed in 1998 & 0.67 & 0.39 & 0.70 & 0.38 \\
\hline Hourly wage 1995 & 134.42 & 73.93 & 127.34 & 60.72 \\
\hline Senior management level 1995 & 0.01 & 0.07 & 0.00 & 0.05 \\
\hline Higher management level 1995 & 0.10 & 0.30 & 0.07 & 0.26 \\
\hline Medium level employee 1995 & 0.21 & 0.41 & 0.17 & 0.38 \\
\hline Lower level employee 1995 & 0.34 & 0.47 & 0.40 & 0.49 \\
\hline Smoker & 0.30 & 0.46 & 0.31 & 0.46 \\
\hline Single & 0.04 & 0.19 & 0.02 & 0.15 \\
\hline Non-native speaker & 0.02 & 0.13 & 0.00 & 0.07 \\
\hline Breast fed child in question & 0.96 & 0.20 & 0.95 & 0.21 \\
\hline Postpartum depression & 0.01 & 0.10 & 0.01 & 0.10 \\
\hline Income 1996 (1,000 DKK) & 118 & 35 & 119 & 36 \\
\hline \multicolumn{5}{|l|}{ Father's Characteristics: } \\
\hline Vocational degree & 0.43 & 0.50 & 0.50 & 0.50 \\
\hline Short further & 0.15 & 0.36 & 0.13 & 0.33 \\
\hline Long further & 0.10 & 0.30 & 0.06 & 0.23 \\
\hline Labor market experience & 11.11 & 5.73 & 11.35 & 5.41 \\
\hline Hourly wage 1995 & 171.22 & 87.75 & 166.60 & 75.64 \\
\hline Senior management level 1995 & 0.03 & 0.18 & 0.02 & 0.13 \\
\hline Higher management level 1995 & 0.14 & 0.35 & 0.09 & 0.28 \\
\hline Medium level employee 1995 & 0.12 & 0.32 & 0.09 & 0.28 \\
\hline Lower level employee 1995 & 0.40 & 0.49 & 0.47 & 0.50 \\
\hline Leave & 0.25 & 0.43 & 0.19 & 0.39 \\
\hline
\end{tabular}

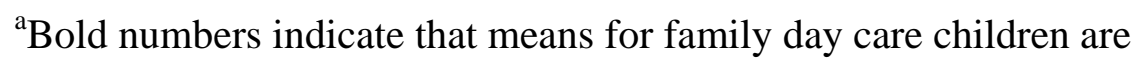
significantly different from those in preschool (5 \% level) 